\title{
A single institutional experience of surgically resected thymic epithelial tumors over 10 years - Clinical outcomes and clinicopathologic features
}

\author{
BEOM KYUNG KIM ${ }^{2 *}$, BYOUNG CHUL CHO ${ }^{1,2^{*}}$, HYE JIN CHOI ${ }^{1,2}$, JOO HYUK SOHN ${ }^{1,2}$, MOO SUK PARK ${ }^{2}$, \\ JOON CHANG ${ }^{2}$, SE KYU KIM ${ }^{2}$, DAE JOON KIM ${ }^{3}$, KYUNG YOUNG CHUNG ${ }^{3}$, \\ CHANG GEOL LEE ${ }^{4}$, JOO HANG KIM ${ }^{1,2}$ and NAE CHOON YOO ${ }^{1,2}$ \\ ${ }^{1}$ Yonsei Cancer Center, Departments of ${ }^{2}$ Internal Medicine, ${ }^{3}$ Thoracic Surgery and ${ }^{4}$ Radiation Oncology, \\ Yonsei University College of Medicine, Seoul 120-752, Korea
}

Received October 16, 2007; Accepted December 28, 2007

\begin{abstract}
Thymic epithelial tumors (TETs) consist of a series of neoplasm that differ morphologically and biologically. Due to its rarity and indolent natural history, large-scale prospective trials have been lacking. This study aimed to evaluate long-term clinical outcomes and clinicopathologic features for TET after surgical resection and adjuvant treatments. One hundred patients who received surgery plus adjuvant radiotherapy \pm chemotherapy for TET (Masaoka stage II-IVa) from 1995 to 2005 were retrospectively reviewed. Masaoka staging systems were adopted, and pathologic results were classified according to World health organization (WHO) histologic classification. After surgery, 55 patients were treated with radiotherapy alone, while 45 with radiotherapy and chemotherapy. The median radiation dose was 50.4 Gy (45-63 Gy) and six cycles of chemotherapy, consisting of doxorubicin, cisplatin, vincristine and cyclophosphamide, were applied every 3-4 weeks. Distributions according to Masaoka stage were as follows; stage II (58 patients), III (21) and IVa (21). According to WHO histology, there were A (3), AB (7), B1 (7), B2 (31), B3 (31) and C (21). With a median follow-up duration of 65 months (8143 months), the 5-year overall survival (OS) and diseasefree survival (DFS) rates were $75.7 \%$ (89.2, 67.9 and $52.1 \%$ in stage II, III and IVa, respectively) and 70.3\% (83, 62.4 and $33.6 \%$ in stage II, III and IVa, respectively). In multivariate analysis, prognostic factors for OS were age, WHO
\end{abstract}

Correspondence to: Dr Nae Choon Yoo, Yonsei Cancer Center, Yonsei University College of Medicine, Seodaemun-gu Shinchondong 134, CPO Box 8044, Seoul 120-752, Korea

E-mail: cbc1971@yuhs.ac

${ }^{*}$ Contributed equally

Key words: thymic epithelial tumor, adjuvant treatment, prognosis, Masaoka stage, WHO histologic classification histology, Masaoka stage, and recurrence, while pleural involvement, WHO histology, and Masaoka stage had significant impacts on DFS. Adjuvant chemotherapy did not alter survival outcomes and recurrence patterns. Pleura was the most common recurrence site (15 patients, 53.6\%), and significantly associated with pleural recurrence-free survival. In conclusion, pleural involvement at diagnosis was the important prognostic factor, in addition to WHO histology and Masaoka stage. To prevent pleural recurrence and prolong survival, innovative therapeutic approaches warrant further investigations.

\section{Introduction}

Thymic epithelial tumor (TET) consists of a series of neoplasm that differ morphologically as well as biologically. It is a rare primary tumor of the anterior mediastinum, which accounts for $20-30 \%$ of all mediastinal neoplasms and $1 \%$ of all reported cancers. Its annual incidence is only 0.15 cases per 100,000 in the United States and due to its rarity and indolent natural history, large-scale prospective randomized trials have been lacking $(1,2)$. Five-year overall survival (OS) rates of $90-94 \%$ and $86-95 \%$ were reported after curative resection for stage I and II tumors, respectively, while stage III and IV patients experienced 5-year OS rates of 56-69\% and 11-50\%, respectively $(3,4)$.

Wide controversies to determine the terminology and classification of TETs existed in the past. Only recently provisional consensus on staging and histologic classifications have been reached (3). Two major factors leading to this consensus building are the current World Health Organization (WHO) criteria for histologic classification, and the suggestion of a modified Masaoka staging system.

Regarding treatment modalities, although surgery remains the mainstay of treatment, adjuvant chemotherapy or radiotherapy has been widely used in many institutes $(4,5)$. Nowadays, many oncologists adopt postoperative mediastinal irradiation as standard for the majority of stage II or higher tumors, even after complete resection (6-9). However, despite postoperative radiotherapy, $>80 \%$ of recurrences still occur 
in the extra-radiation field in the thorax, such as pleural dissemination, therefore, various attempts, including higher dose or extended field irradiations to the entire thorax as well as adjuvant chemotherapy, have been evaluated $(4,8,10)$. However, so far, neither guidelines nor randomized trials on treatment strategies exist.

The aim of this study was to evaluate long-term clinical outcomes and clinicopathologic features in TET after surgical resection and adjuvant treatments.

\section{Materials and methods}

Patients. We retrospectively reviewed the medical records of patients with TETs treated at Severance Hospital, Seoul, Korea, between 1995 and 2005. Patients with TETs (Masaoka stage II-IVa) who were eligible for postoperative adjuvant radiotherapy and chemotherapy were enrolled. Patients with stage IVa were also included in this study if pleural or pericardial disseminated tumor was completely resected. Patients with macroscopic residual tumor after resection (R2 resection) were excluded.

Histologic classification and clinical staging. Pathologic results were confirmed by one experienced pathologist who was blind to the clinical data, according to the WHO histologic classification. Hematoxylin and eosin-stained sections were available, and at least five sections were examined for histologic typing of the tumor for every patient. Additional sections were examined if a microscopically positive margin was suspected. The stage was determined by review of the surgical and pathologic reports, and the staging system of Masaoka et al (11) was adopted.

Surgery. Surgical procedures included complete removal of thymic, mediastinal fat tissue, and any suspicious lesions. Furthermore, we performed an exploration of the entire thorax, including both pleural cavities, via median sternotomy to determine if satellite lesions were present, and to confirm that no secondary neoplasms were present. Surgeons tried to completely remove all the involved pleural and pericardial lesions, if surgically possible, even in patients with stage IVa tumor.

Adjuvant chemotherapy. The ADOC regimen was used for a total of six cycles every 3-4 weeks, and consisted of doxorubicin $\left(40 \mathrm{mg} / \mathrm{m}^{2}\right)$ and cisplatin $\left(50 \mathrm{mg} / \mathrm{m}^{2}\right)$ administered intravenously on day 1 , vincristine $\left(0.6 \mathrm{mg} / \mathrm{m}^{2}\right)$ on day 3 , and cyclophosphamide $\left(700 \mathrm{mg} / \mathrm{m}^{2}\right)$ on day 4 . The first three cycles of chemotherapy were initiated within 4 weeks after surgery, followed by radiotherapy and then a further three cycles of chemotherapy.

Adjuvant radiotherapy. Radiotherapy was administered with a 10-MV linear accelerator in a three-way manner (anterior/ right anterior oblique/left anterior oblique) after computed tomography (CT). The irradiation field that covered the primary tumor bed with a margin of $\sim 1-2 \mathrm{~cm}$ was applied to the entire population at the median target dose of $5040 \mathrm{cGy}$ (180 cGy/fraction) for 5-6 weeks. A similar method was applied to patients with stage IVa tumors, taking into consideration preoperative radiological studies and intraoperative findings on the extent of the tumor; the scheduled doses were slightly higher (5400-6300 cGy) according to the decision of the radiation oncologists. Prophylactic irradiation to the supraclavicular fossae was not performed. Irradiation to the thorax was started within at least 5 weeks from the date of operation. In patients given adjuvant chemotherapy, it was started after three cycles of chemotherapy, that is, within 4 or 5 months after surgery.

Initial workup and follow-up. Initial evaluation included a complete history and physical examination with special attention to symptoms often associated with TETs; laboratory procedures included a complete blood cell count, blood urea nitrogen, creatinine and liver function tests. Chest radiography and CT were also included in the initial workup, and chest magnetic resonance imaging was performed, if necessary, to assess the involvement of major vessels and surrounding organs.

Follow-up chest CT was performed within 4-6 weeks following completion of radiotherapy. These imaging studies were also performed after each three cycles of chemotherapy. After completion of scheduled adjuvant treatment, patients were seen at 6-month intervals, and chest CT, whole-body bone scanning, and laboratory tests (similar to the initial workup) were performed at each visit.

Routine assessment of cardiac function before and after chemotherapy was not performed unless patients presented with major symptoms and signs of heart failure because they received a relatively lower cumulative dose of doxorubicin (240 mg/m² during six cycles) (12).

Toxicity was graded according to the Common Toxicity Criteria of the National Cancer Institute, version 1.0 or 2.0 (available from http://ctep.info.nih.gov/reporting/ctc.html).

Statistical analysis. Univariate analysis was performed by the Kaplan-Meier method to assess prognostic factors for OS and disease-free survival (DFS), with comparison using a logrank test for initial analysis. Subsequent multivariate analysis was performed using the Cox regression model to identify independent prognostic factors. Differences in continuous variables were statistically examined with Student's t-test, and those of the categorical variables using the $\chi^{2}$ test. OS was measured from the date of operation until the day of death or last follow-up visit. DFS was also measured from the date of operation until the date of recurrence. A P-value of 0.05 was chosen for statistical significance. Statistical analysis was performed using SPSS software version 12.0 (SPSS, Chicago, IL, USA).

\section{Results}

Baseline clinical characteristics. Patient characteristics are summarized in Table I. The median age was 48 years (range, 20-76) and 63 patients were male. All patients had a good performance status at the beginning of adjuvant treatment. Fifty-eight stage II (58\%), 21 stage III (21\%) and 21 stage IVa $(21 \%)$ TETs were identified, and the most common WHO histologic subtypes were B2 and B3, accounting for $62 \%$. Seventy-eight patients underwent complete resection with 
Table I. Patients characteristics.

\begin{tabular}{|c|c|}
\hline Characteristics & No. $(\%)$ \\
\hline $\begin{array}{l}\text { Median age at diagnosis, } \\
\text { years (range) }\end{array}$ & $48(20-76)$ \\
\hline \multicolumn{2}{|l|}{ Sex } \\
\hline Male/Female & $63(63) / 37(37)$ \\
\hline Presence of myasthenia gravis & $52(52)$ \\
\hline \multicolumn{2}{|l|}{ Performance status (ECOG) } \\
\hline 0 & $30(30)$ \\
\hline 1 & $70(70)$ \\
\hline \multicolumn{2}{|l|}{ Masaoka stage } \\
\hline II & $53(53)$ \\
\hline III & $26(26)$ \\
\hline IVa & $21(21)$ \\
\hline \multicolumn{2}{|l|}{ WHO classification } \\
\hline A & 3 (3) \\
\hline $\mathrm{AB}$ & 7 (7) \\
\hline B1 & 7 (7) \\
\hline $\mathrm{B} 2$ & $31(31)$ \\
\hline B3 & $31(31)$ \\
\hline $\mathrm{C}$ & $21(21)$ \\
\hline \multicolumn{2}{|l|}{ Resection status } \\
\hline Complete resection (R0) & $78(78)$ \\
\hline $\begin{array}{l}\text { Resection with microscopic } \\
\text { residues }(\mathrm{R} 1)\end{array}$ & $21(22)$ \\
\hline \multicolumn{2}{|l|}{ Treatment modality } \\
\hline $\mathrm{OP}+\mathrm{RT}$ & $55(55)$ \\
\hline $\mathrm{OP}+\mathrm{RT}+\mathrm{CT}$ & $45(45)$ \\
\hline Median radiation dose, cGy (range) & $5040(4500-6300)$ \\
\hline $\begin{array}{l}\text { Median follow-up duration, } \\
\text { months (range) }\end{array}$ & $5(8-143)$ \\
\hline Relapse & $28(28)$ \\
\hline Death & $22(22)$ \\
\hline
\end{tabular}

OP, operation; RT, radiotherapy; CT, chemotherapy.

microscopically negative margin (R0 resection). Complete resection rate was significantly higher in stage II (54 of 58 patients; 93.1\%) than in stage III/IVa (24 of 42 patients; $57.1 \%, \mathrm{P}=0.009)$.

Association of WHO histologic subtypes with Masaoka stages. The association between the WHO histologic subtype and Masaoka stage are given in Table II. More than two-thirds of type A, AB, B1 and B2 TETs were categorized as Masaoka stages II. Conversely, more than half of types B3 and $\mathrm{C}$ were
Table II. Masaoka stage with reference to WHO histologic classification.

\begin{tabular}{lrrrr}
\hline & \multicolumn{3}{c}{ Stage } & \\
\cline { 2 - 4 } WHO histology & II & III & IVa & Total \\
\hline A & 2 & 1 & 0 & 3 \\
AB & 5 & 2 & 0 & 7 \\
B1 & 6 & 1 & 0 & 7 \\
B2 & 22 & 5 & 4 & 31 \\
B3 & 18 & 6 & 7 & 31 \\
C & 5 & 6 & 10 & 21 \\
Total & 58 & 21 & 21 & 100 \\
\hline
\end{tabular}

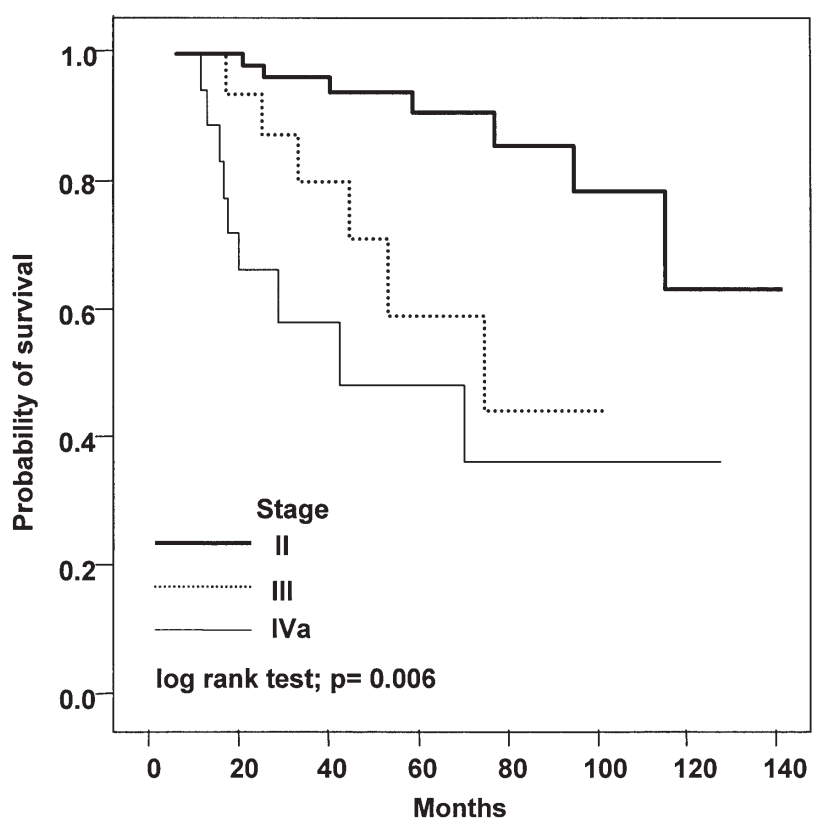

Figure 1. Overall survival according to Masaoka stage in entire population.

detected in advanced stages (stage III and IV). There was a significant correlation between Masaoka staging and WHO histologic types $(\mathrm{P}=0.032)$.

Prognostic factors for $O S$ and DFS. In univariate analysis, age $(\mathrm{P}=0.002)$, WHO histologic classification $(\mathrm{P}<0.001)$, myasthenia gravis $(\mathrm{P}=0.013)$, resection status $(\mathrm{P}=0.007)$, Masaoka stage $(\mathrm{P}=0.006)$ and recurrence $(\mathrm{P}=0.005)$ had statistically significant impact on OS. Subsequent multivariate analysis showed age $(\mathrm{P}=0.025)$, WHO histologic classification $(\mathrm{P}=0.022)$, Masaoka stage $(\mathrm{P}=0.04)$ and recurrence $(\mathrm{P}=0.005)$ as independent prognostic factors (Table III). Concerning DFS, WHO histologic classification $(\mathrm{P}=0.005)$, myasthenia gravis $(\mathrm{P}=0.006)$, resection status $(\mathrm{P}=0.017)$, Masaoka stage $(\mathrm{P}=0.005)$, and pleural invasion at diagnosis $(\mathrm{P}=0.002)$ were identified as significant in univariate analysis, while WHO classification $(\mathrm{P}=0.01)$, Masaoka stage $(\mathrm{P}=0.04)$ and pleural 
Table III. Prognostic factors affecting 5-year overall survival and disease-free survival.

\begin{tabular}{|c|c|c|c|c|}
\hline \multirow[b]{2}{*}{ Variables } & \multicolumn{2}{|c|}{ Overall survival } & \multicolumn{2}{|c|}{ Disease-free survival } \\
\hline & Univariate analysis $^{\mathrm{a}}$ & Multivariate analysis $^{\mathrm{a}}$ & Univariate analysis $^{\mathrm{a}}$ & Multivariate analysis \\
\hline Age ( $<55$ vs $\geq 55$ years $)$ & 0.002 & 0.025 & 0.342 & - \\
\hline Sex (male vs female) & 0.220 & - & 0.244 & - \\
\hline $\begin{array}{l}\text { WHO type (A-B1 vs B2 vs } \\
\text { B3 vs C) }\end{array}$ & $<0.001$ & 0.022 & 0.005 & 0.01 \\
\hline Myasthenia gravis (Yes vs No) & 0.013 & - & 0.006 & - \\
\hline Radiation dose ( $\geq 5040$ vs $<5040$ ) & 0.121 & - & 0.267 & - \\
\hline Resection status (R0 vs R1) & 0.007 & - & 0.017 & - \\
\hline Modality $(\mathrm{OP}+\mathrm{RT}$ vs $\mathrm{OP}+\mathrm{RT}+\mathrm{CT})$ & 0.078 & - & 0.05 & - \\
\hline Stage (II vs III/IVa) & 0.006 & 0.04 & 0.005 & 0.04 \\
\hline Recurrence (Yes vs No) & 0.005 & 0.005 & & \\
\hline Pleura invasion (Yes vs No) & & & 0.002 & 0.007 \\
\hline
\end{tabular}

${ }^{\text {aD }}$ ata are expressed as p-value. OP, operation; RT, radiotherapy; CT, chemotherapy.

Table IV. Patterns of recurrences.

\begin{tabular}{|c|c|c|c|c|c|c|c|}
\hline \multirow[b]{3}{*}{ Stage } & \multirow[b]{3}{*}{ Modality } & \multirow[b]{3}{*}{$\begin{array}{l}\text { No. of } \\
\text { patients }\end{array}$} & \multicolumn{5}{|c|}{ Site of recurrences ${ }^{a}$} \\
\hline & & & \multirow[b]{2}{*}{ Infield } & \multicolumn{4}{|c|}{ Extrafield } \\
\hline & & & & Lung & $\begin{array}{c}\text { Pleura } \\
\text { (Seeding/Mass) }\end{array}$ & Pericardium & Distant \\
\hline \multirow[t]{2}{*}{ II } & $\mathrm{OP}+\mathrm{RT}$ & 35 & 2 & 3 & $5 \quad(4 / 1)$ & 0 & 2 \\
\hline & $\mathrm{OP}+\mathrm{RT}+\mathrm{CT}$ & 23 & 0 & 1 & $1 \quad(1 / 0)$ & 0 & 1 \\
\hline \multirow[t]{2}{*}{ III, IV } & $\mathrm{OP}+\mathrm{RT}$ & 20 & 0 & 0 & $3 \quad(2 / 1)$ & 0 & 0 \\
\hline & $\mathrm{OP}+\mathrm{RT}+\mathrm{CT}$ & 22 & 0 & 7 & $6(4 / 2)$ & 2 & 0 \\
\hline Total & & 100 & 2 & 11 & $15(11 / 4)$ & 2 & 3 \\
\hline
\end{tabular}

$\mathrm{RT}$, radiotherapy; CT, chemotherapy. ${ }^{\text {an }}$ patients with two sites of first recurrence, both sites were scored.

invasion $(\mathrm{P}=0.007)$ were identified as independent prognostic factors in multivariate analysis (Table III; Figs. 1 and 2).

Patterns of recurrence. Recurrence was observed in 28 patients $(28 \%)$, with a median survival of 10.8 months after recurrence. Patterns of recurrence are described in Table IV. Only two patients $(7.1 \%)$ experienced intra-radiation field recurrence. Among the extra-radiation field recurrences, the pleura was the most frequent site of treatment failure (15 patients, $53.6 \%$ ), followed by the lung (11 patients, 39.3\%). Of 15 pleural recurrences, 11 patients $(73.3 \%)$ had pleural dissemination remote from the primary tumor bed and irradiation field. Ten patients experienced only pleural recurrence, and five had simultaneous recurrences in the pericardium $(n=2)$, mediastinum $(n=1)$ and lung $(n=2)$. Three patients experienced distant metastasis (two in the liver and one in bone).

Pleural recurrence. When tumors recurred, pleural invasion at the time of surgery predicted the higher overall incidence of pleural involvement $(23.2 \%$ in pleura-positive versus $8.7 \%$ in pleura-negative patients; $\mathrm{P}=0.021$ ). Furthermore, pleural 


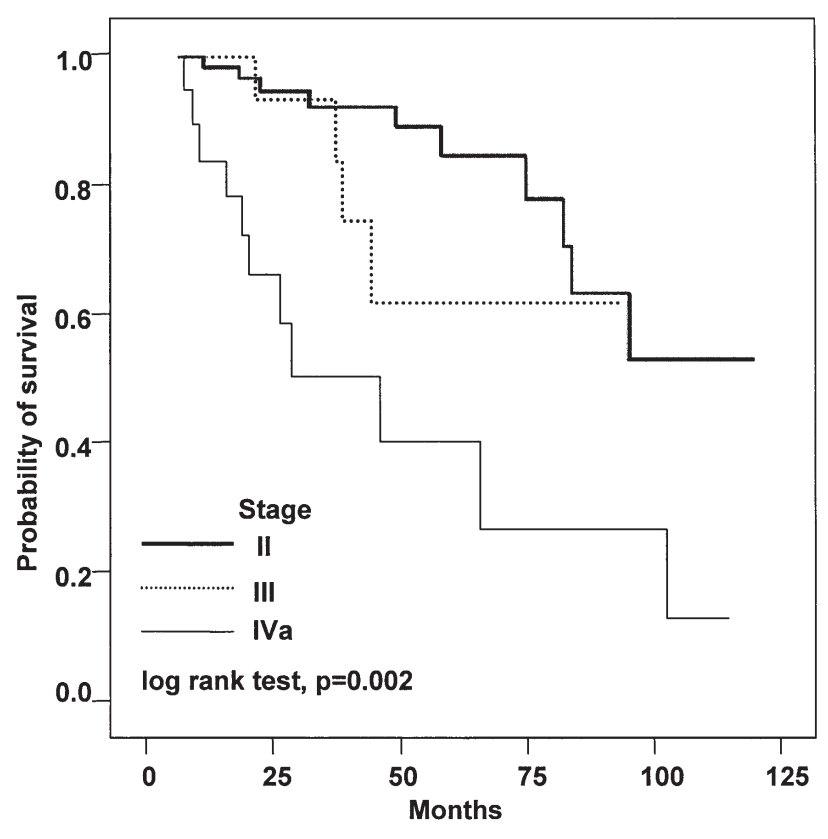

Figure 2. Disease-free survival according to Masaoka stage in entire population.

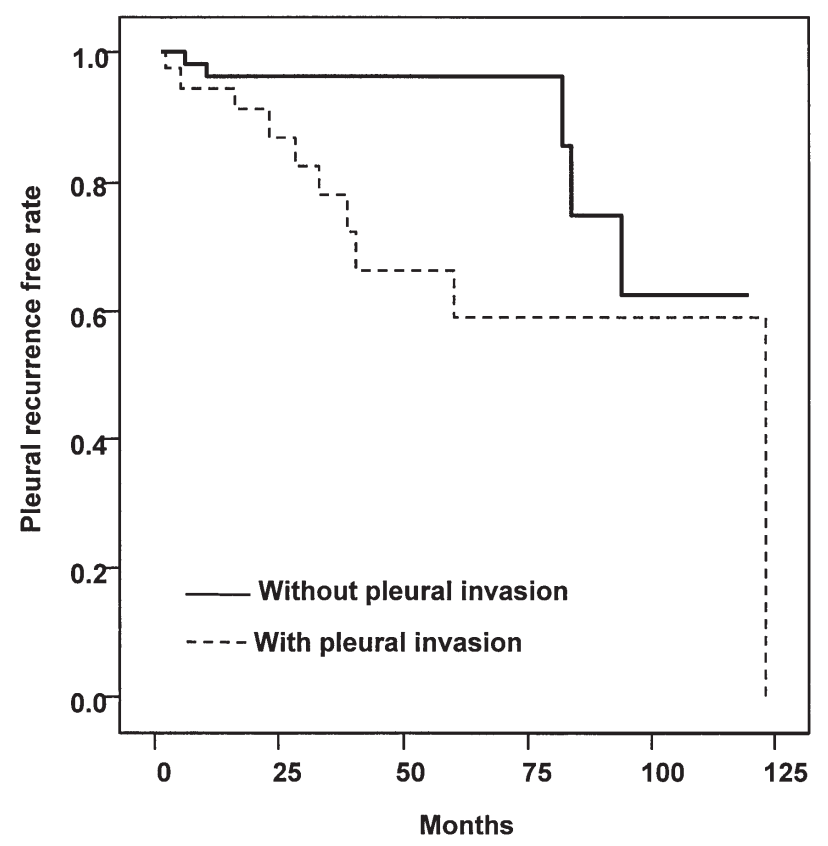

Figure 3. Pleural recurrence-free survival curves according to pleura invasion at diagnosis.

invasions at diagnosis led to longer pleural recurrence-free survival (Fig. 3).

Management after recurrence. Recurrent TET was treated with a palliative approach, except in three patients who did not receive any treatment due to poor performance status or treatment refusal. Seven patients underwent surgical resection in combination with chemotherapy or radiotherapy. Fifteen patients received only chemotherapy, one only radiotherapy and two received both. The ADOC regimen was applied as
Table V. Chemotherapy related adverse events.

\begin{tabular}{lrrrr}
\hline Adverse events & $\begin{array}{c}\text { Grade 1-2 } \\
\mathrm{n}(\%)\end{array}$ & $\begin{array}{c}\text { Grade 3-4 } \\
\mathrm{n}(\%)\end{array}$ \\
\hline Neutropenia & 6 & $(26.7)$ & 21 & $(46.7)$ \\
Anemia & 15 & $(33.3)$ & 0 & $(0)$ \\
Thrombocytopenia & 9 & $(20)$ & 0 & $(0)$ \\
Fatigue & 27 & $(60)$ & 0 & $(0)$ \\
Mucositis & 20 & $(44.4)$ & 0 & $(0)$ \\
Nausea & 12 & $(26.6)$ & 12 & $(26.6)$ \\
Vomiting & 13 & $(26.8)$ & 10 & $(24.3)$ \\
Diarrhea & 10 & $(22.2)$ & 0 & $(0)$ \\
Peripheral neuropathy & 14 & $(31.1)$ & 0 & $(0)$ \\
Alopecia & 45 & $(100)$ & & - \\
\hline
\end{tabular}

Toxicities were assessed by the Common Toxicity Criteria of the National Cancer Institute, version 1.0 or 2.0.

palliative chemotherapy for eight chemotherapy-naive patients, and taxane-based combination regimens for seven patients who were previously treated with the ADOC regimen.

Treatment toxicity. In terms of radiation toxicity, all patients completed the scheduled radiotherapy without major complications. No patients reported any late toxicity.

The ADOC regimen was well tolerated (Table V). Among grade III/IV hematologic toxicity, only neutropenia was observed in 21 patients $(46.7 \%)$, without anemia or thrombocytopenia. Common non-hematologic toxicity included alopecia $(100 \%)$, fatigue $(60 \%)$ and nausea/vomiting (53/ $51 \%)$. The only grade III/IV non-hematologic toxicity was nausea/vomiting (26/24\%). No treatment-related mortality occurred, and all patients completed the six cycles of ADOC chemotherapy without dose reduction. Four cases $(8.8 \%)$ of chemotherapy delay occurred due to grade III/IV neutropenia $(n=3)$ and nausea/vomiting $(n=1)$.

\section{Discussion}

TET is a kind of neoplasm including tumors that differ morphologically as well as biologically and only recently provisional consensus on staging and histologic classifications have been reached. On treatment strategies, complete surgical resection is the treatment of choice for TETs and the most important indicator of long term prognosis (13-15). However, intrathoracic recurrences have been reported in approximately $28-57 \%$ of patients with stage II and III tumors, therefore, most centers currently consider postoperative radiotherapy except for patients with stage I disease. Furthermore, to prevent the extra-radiation field, additional adjuvant treatments, including chemotherapy, have been tried despite some controversy (6-8,13-17).

In the present study, we investigated the correlation between the WHO histologic subtypes and the Masaoka staging system, and identified these as two independent 
prognostic factors for survival, similar to those of other investigations $(3,4,8,18-21)$. Interestingly, we found the importance of the pleural factor, in addition to Masaoka stage, especially for DFS. As pleural-based recurrence is the most common pattern of failure, and is closely correlated with the incidence of pleural involvement at diagnosis, it may be a strong predictor for DFS, in addition to the Masaoka stage $(22,23)$. Actually, pleural involvement at diagnosis was significantly correlated with pleural recurrence-free survival. This also suggests that some patients with pleural involvement at diagnosis may already have latent microscopic pleural dissemination at the time of surgery, even in lower stage disease $(10,22)$.

In contrast to previous studies, a positive resection margin did not independently influence OS and DFS on multivariate analysis $(2,16,24,25)$. Since complete resection was significantly higher in stage II than in stage III/IVa, the final influence on survival may be determined more accurately by clinicopathologic status rather than by resection status alone (26). Furthermore, adequate postoperative radiotherapy may overcome the burden of microscopic residual disease in the primary tumor bed $(8,9,21)$.

The ADOC single chemotherapy regimen was used in our study. It is regarded as highly active and well tolerated, demonstrating overall response rate of $50-80 \%$ for unresectable or metastatic TET and excellent compliance $(4,14,27,28)$.

No toxic deaths were observed and each patient completed the scheduled six cycles of chemotherapy with manageable toxicity.

Considering the high response rate of the ADOC regimen, and the chemo-sensitivity of TETs, there may be a potential rationale for using adjuvant chemotherapy to prevent extraradiation field recurrence, and prolong survivals $(4,10,14,15)$. However, adjuvant chemotherapy did not alter the survival outcomes and recurrence patterns in our study. The potential reasons for this lack of additional benefit are as follows; first, given the relatively small number of recurrences and considering the indolent nature of TETs, it is difficult to accurately validate the efficacy of chemotherapy (2). Second, considering that the pleura is the most frequent site of recurrence, systemic administration of chemotherapeutic agents might not be sufficient to maintain adequate drug concentrations in the pleural cavity (29-31). Large-scale prospective trials are needed to more accurately assess the role of adjuvant chemotherapy.

In conclusion, although there was a clear association between two systems, the Masaoka stage and WHO histotype were independent prognostic factors for survival. Furthermore, pleural involvement at diagnosis was another significant prognostic variable for recurrence. As the most common patterns of recurrence occurred in the extra-radiation field, that is, pleura, large-scale prospective trials on more innovative therapeutic approaches are needed to reduce pleural recurrence and prolong survival.

\section{References}

1. Engels EA and Pfeiffer RM: Malignant thymoma in the United States: demographic patterns in incidence and associations with subsequent malignancies. Int J Cancer 1: 546-551, 2003.
2. Ruffini E, Mancuso M, Oliaro A, Casadio C, Cavallo A, Cianci R, Filosso PL, Molinatti M, Porrello C, Cappello N and Maggi G: Recurrence of thymoma: analysis of clinicopathologic features, treatment, and outcome. J Thorac Cardiovasc Surg 113: 55-63, 1997.

3. Kim DJ, Yang WI, Choi SS, Kim KD and Chung KY: Prognostic and clinical relevance of the World Health Organization schema for the classification of thymic epithelial tumors: a clinicopathologic study of 108 patients and literature review. Chest 127: 755-761, 2005.

4. Johnson SB, Eng TY, Giaccone G and Thomas CR: Thymoma update for the new millennium. Oncologist 6: 239-246, 2001.

5. Kesler KA, Wright GD and Loehrer PJ Sr: Thymoma: current medical and surgical management. Semin Neurol 24: 63-73, 2004

6. Curran WJ, Kornstein MJ, Brooks JJ and Turrisi AT: Invasive thymoma: the role of mediastinal irradiation following complete or incomplete surgical resection. J Clin Oncol 6: 1722-1727, 1988.

7. Devita V, Hellman S and Rosenberg S: Cancer: Principles and Practice of Oncology. 4th edition. Lippincott Co., Philadelphia, PA, 2001.

8. Gripp S, Hilgers K, Wurm R and Schmitt G: Thymoma: prognostic factors and treatment outcomes. Cancer 83: 1495-1503, 1998.

9. Venuta F, Rendina EA, Longo F, De Giacomo T, Anile M, Mercadante E, Ventura L, Osti MF, Francioni F and Coloni GF: Long-term outcome after multimodality treatment for stage III thymic tumors. Ann Thorac Surg 76: 1866-1872, 2003.

10. Ogawa K, Uno T, Toita T, Onishi H, Yoshida H, Kakinohana Y, Adachi G, Itami J, Ito $\mathrm{H}$ and Murayama S: Postoperative radiotherapy for patients with completely resected thymoma: a multi-institutional, retrospective review of 103 patients. Cancer 94: 1405-1413, 2002.

11. Masaoka A, Monden Y, Nakahara K and Tanioka T: Follow-up study of thymomas with special reference to their clinical stages. Cancer 48: 2485-2492, 1981.

12. Von Hoff DD, Layard MW, Basa P, Davis HL Jr, von Hoff AL, Rozencweig M and Muggia FM: Risk factors for doxorubicininduced congestive heart failure. Ann Intern Med 91: 710-717, 1979.

13. Nakahara K, Ohno K, Hashimoto J, Maeda H, Miyoshi S, Sakurai M, Monden Y and Kawashima Y: Thymoma: results with complete resection and adjuvant postoperative irradiation in 141 consecutive patients. J Thorac Cardiovasc Surg 95: 1041-1047, 1988 .

14. Giaccone G: Treatment of malignant thymoma. Curr Opin Oncol 17: 140-146, 2005.

15. Thomas CR, Wright CD and Loehrer PJ: Thymoma: state of the art. J Clin Oncol 17: 2280-2289, 1999.

16. Kondo K and Monden Y: Therapy for thymic epithelial tumors: a clinical study of 1,320 patients from Japan. Ann Thorac Surg 76: 878-884, 2003.

17. Mangi AA, Wain JC, Donahue DM, Grillo HC, Mathisen DJ and Wright CD: Adjuvant radiation of stage III thymoma: is it necessary? Ann Thorac Surg 79: 1834-1839, 2005.

18. Fang W, Chen W, Chen G and Jiang Y: Surgical management of thymic epithelial tumors: a retrospective review of 204 cases. Ann Thorac Surg 80: 2002-2007, 2005.

19. Strobel P, Bauer A, Puppe B, Kraushaar T, Krein A, Toyka K, Gold R, Semik M, Kiefer R, Nix W, Schalke B, MullerHermelink HK and Marx A: Tumor recurrence and survival in patients treated for thymomas and thymic squamous cell carcinomas: a retrospective analysis. J Clin Oncol 22: 1501-1509, 2004.

20. Park MS, Chung KY, Kim KD, Yang WI, Chung JH, Kim YS, Chang J, Kim JH, Kim SK and Kim SK: Prognosis of thymic epithelial tumors according to the new World Health Organization histologic classification. Ann Thorac Surg 78: 992-997, 2004.

21. Eralp Y, Aydiner A, Kizir A, Kaytan E, Oral EN and Topuz E: Resectable thymoma: treatment outcome and prognostic factors in the late adolescent and adult age group. Cancer Invest 21: 737-743, 2003.

22. Haniuda M, Miyazawa M, Yoshida K, Oguchi M, Sakai F, Izuno I and Sone S: Is postoperative radiotherapy for thymoma effective? Ann Surg 224: 219-224, 1996.

23. Haniuda M, Morimoto M, Nishimura H, Kobayashi O, Yamanda $\mathrm{T}$ and Iida F: Adjuvant radiotherapy after complete resection of thymoma. Ann Thorac Surg 54: 311-315, 1992. 
24. Zhu G, He S, Fu X, Jiang G and Liu T: Radiotherapy and prognostic factors for thymoma: a retrospective study of 175 patients. Int J Radiat Oncol Biol Phys 60: 1113-1119, 2004.

25. Myojin M, Choi NC, Wright CD, Wain JC, Harris N, Hug EB, Mathisen DJ, Lynch T, Carey RW, Grossbard M, Finkelstein DM and Grillo HC: Stage III thymoma: pattern of failure after surgery and postoperative radiotherapy and its implication for future study. Int J Radiat Oncol Biol Phys 46: 927-933, 2000.

26. Okumura M, Ohta M, Tateyama H, Nakagawa K, Matsumura A, Maeda $\mathrm{H}$, Tada $\mathrm{H}$, Eimoto T, Matsuda $\mathrm{H}$ and Masaoka A: The World Health Organization histologic classification system reflects the oncologic behavior of thymoma: a clinical study of 273 patients. Cancer 94: 624-632, 2002.

27. Fornasiero A, Daniele O, Ghiotto C, Piazza M, Fiore-Donati L, Calabro F, Rea F and Fiorentino MV: Chemotherapy for invasive thymoma. A 13-year experience. Cancer 68: 30-33, 1991.
28. Berruti A, Borasio P, Gerbino A, Gorzegno G, Moschini T, Tampellini M, Ardissone F, Brizzi MP, Dolcetti A and Dogliotti L: Primary chemotherapy with adriamycin, cisplatin, vincristine and cyclophosphamide in locally advanced thymomas: a single institution experience. Br J Cancer 81: 841-845, 1999.

29. Tsujitani S, Fukuda K, Saito H, Kondo A, Ikeguchi M, Maeta M and Kaibara N: The administration of hypotonic intraperitoneal cisplatin during operation as a treatment for the peritoneal dissemination of gastric cancer. Surgery 131: 104, 2002.

30. Rusch VW, Figlin R, Godwin D and Piantadosi S: Intrapleural cisplatin and cytarabine in the management of malignant pleural effusions: a Lung Cancer Study Group trial. J Clin Oncol 9: 313-319, 1991.

31. Katano K, Tsujitani S, Maeta M, Fukuda K, Oka S, Hisamitsu K, Ikeguchi $\mathrm{M}$ and Kaibara N: Pharmacokinetics of intraoperative intrapleural cisplatin chemotherapy of various osmolarities in cases of esophageal cancer. Oncol Rep 8: 605-609, 2001. 